\title{
Between a rock and a hard place
}

\author{
Regent Lee, ${ }^{1,2}$ Mark Bratby, ${ }^{3}$ Raman Uberoi, ${ }^{3}$ Ashok Handa, ${ }^{2}$ Linda Hands ${ }^{2}$
}

${ }^{1}$ Department of Cardiovascular Medicine, University of Oxford, Oxford, UK;

2Department of Vascular surgery, John Radcliffe Hospital, UK;

${ }^{3}$ Department of Interventional Radiology, John Radcliffe Hospital, Oxford, UK

Correspondence to Dr Regent Lee, regent.lee@cardiov.ox.ac.uk

\section{Summary}

The authors present the case of a patient who presented with acute coronary syndrome requiring percutaneous coronary intervention. He was incidentally diagnosed with a large abdominal abdominal aortic aneurysm which developed acute inflammatory features with rapid sac expansion and imminent rupture. This short report aims to highlight several dilemma that confronted us during the management of this patient.

\section{BACKGROUND}

Inflammatory abdominal aortic aneurysm (AAA) is an interesting disease entity and often poses significant management challenges.

This report chronicles the acute development of inflammatory changes in a large AAA with rapid expansion towards imminent rupture. The rapid progression of aneurysm pathology occurred in the context of a patient who presented with acute coronary syndrome (ACS) and required urgent percutaneous coronary intervention and necessitating dual antiplatelet therapy.

We hope to highlight some of the dilemma that confronted us during the treatment episode. It is still difficult to conclude what would have been a better management strategy: to temporise surgery and minimise cardiac morbidity, or to expedite surgery and accept the surgical risk.

\section{CASE PRESENTATION}

In June 2010, a 69-year-old male presented to us with nonST-elevation ACS with incidental diagnosis of an AAA on physical examination. CT scan confirmed a large $(6 \mathrm{~cm})$ infra-renal AAA with a short and conical infra-renal neck, which was considered not suitable for endovascular repair (figure 1A). Decision was made to proceed to percutaneous coronary revascularisation (PCI) immediately with a view of staged open surgical repair (OSR) of AAA at a subsequent admission.

PCI was performed via a right radial artery approach with bare metal stents (BMS) inserted in the right coronary artery and obtuse marginal branch of the circumflex artery. The procedure proceeded without complication and the patient was discharged the following day in accordance to local practice. Dual antiplatelet therapy of aspirin with clopidogrel was prescribed for a minimum of 6 weeks prior to OSR of AAA.

Within 24 h of discharge from the hospital, the patient represented to the hospital with gradual worsening of lower back and left-sided abdominal pain. Physical examination revealed significant tenderness in the left upper and lower quadrant of the abdomen without peritonism. Repeat CT angiogram (CTA) was performed immediately to rule out acute rupture of the AAA (figure 1B).

The images showed no evidence of acute rupture of the AAA and the dimensions of the aneurysm remained unchanged in comparison to the images obtained 4 days prior. However, stranding of the periaortic tissue was observed throughout the aneurysmal segment, suggesting the diagnosis of an inflammatory AAA (IAAA). The patient remained afebrile but laboratory tests showed acute neutrophilia $\left(10.8 \times 10^{9} / 1\right)$ and raised $C$ reactive protein (148 mg/l).

Due to the history of recent PCI in the setting of ACS and the new diagnosis of IAAA, the patient was treated medically with corticosteroids with view to settle the acute inflammation and to temporise to OSR. Dual antiplatelet therapy with aspirin and clopidogrel was continued throughout this period in view of the recent PCI. His pain symptoms resolved promptly within $48 \mathrm{~h}$ of steroid therapy but suddenly deteriorated with recurrence of abdominal pain on the third day. Repeat CTA demonstrated the progression of aneurysm dimension to $8 \mathrm{~cm}$ with acute haemorrhage into the mural thrombus within the AAA (figure 1C).

\section{INVESTIGATIONS}

- Serial CTAs were performed for this patient at the following time points: upon presentation, 5 days after presentation and 7 days after presentation.

- Blood cultures obtained during admission remained negative for bacterial growth.

\section{DIFFERENTIAL DIAGNOSIS}

- Mycotic abdominal aortic aneurysm with rapid expansion: this diagnosis was ruled out as serial blood cultures taking during the admission remained negative for bacterial growth.

\section{TREATMENT}

Emergency OSR was performed in view of the pending aneurysm rupture. Inflammatory change of the aortic wall 


\section{BMJ Case Reports}
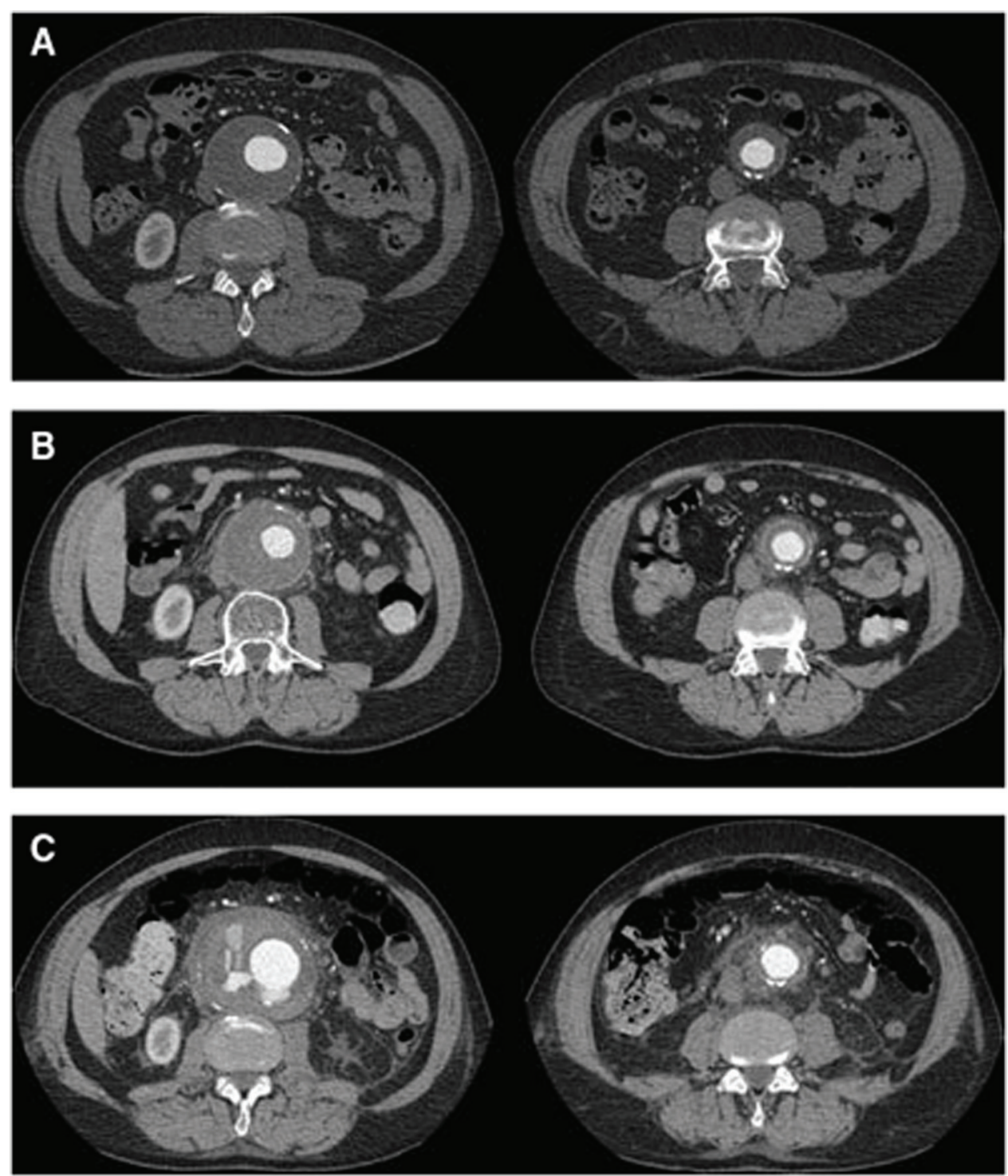

Figure 1 Rapid enlargement and subsequent intramural haemorrhage of infra-renal aortic aneurysm. These CT angiograms (CTA) on the same axial section of the aortic aneurysm were taken from three separate studies within a seven day period. (A) CT angiogram showing an infra-renal aortic aneurysm measuring $60 \mathrm{~mm}$ in maximal AP diameter. (B) CT angiogram showing acute inflammatory changes of the periaortic tissue with no change of the aneurysm dimension. (C) CT angiogram demonstrating progression of aneurysm dimension to $8 \mathrm{~mm}$. Acute extravasation into the mural thrombus is noted.

and surrounding retro-peritoneal tissue was confirmed. A small haematoma was observed around the left renal vein, heralding imminent rupture of the aneurysm. Aneurysm repair of the infra-renal aorta was performed with a 20 $\mathrm{mm}$ straight polyester graft (Braun, Tuuttlingen/Germany). Apart from an intraoperative blood loss of $1200 \mathrm{ml}$ leading to one unit of packed cell transfusion postoperatively, there was no perioperative complication.

\section{OUTCOME AND FOLLOW-UP}

The patient made a prompt recovery from surgery and was discharged home 6 days after the operation. Patient remained well as of 9 months after the operation.

\section{DISCUSSION}

Optimal timing of surgical management for this incidental large AAA was complicated by several considerations.
At the diameter of $6.0 \mathrm{~cm}$, prompt surgical repair of the AAA was warranted to prevent spontaneous rupture. Urgency of surgical repair was further underscored by anecdotal reports of increased risk of aneurysm rupture after other invasive procedures such as coronary revascularisation $^{12}$ and the new onset of acute symptoms related to the inflammatory changes of the aneurysm. In the setting of recent coronary stent implantation after an ACS, he was at increased risk of perioperative myocardial ischaemia, myocardial infarction and death. ${ }^{3}$ The presence of intense periaortic inflammation would pose significant technical challenge for open surgical repair due to the adherence of adjacent tissues such as the renal vein, vena cava, duodenum and ureters. ${ }^{4}$ The risk of intraoperative bleeding could be considerable, especially while the patient received dual antiplatelet therapy. 


\section{BMJ Case Reports}

Current guidelines recommended that patients treated with BMS should complete a minimum of 4 weeks of dual antiplatelet therapy before undergoing non-cardiac surgery. ${ }^{3}$ Medical therapy with corticosteroids or anti-inflammatory therapy might be useful as a temporising measure for IAAA prior to definitive surgical treatment of large aneurysms. ${ }^{4} 5$ On balance, we opted for corticosteroid therapy for the IAAA in the interim and aimed for staged OSR 6 weeks post PCI after cessation of clopidogrel.

Despite the potential risks, emergency OSR was deemed necessary with subsequent acute deterioration of symptoms and imaging finding of rapid expansion of the size of the aneurysm with new haemorrhage into the mural thrombus. Although there was no evidence of aneurysm rupture on the latest CTA, the presence of new bleeding into the mural thrombus was reported to be associated with impending AAA rupture. ${ }^{6}$ In this case diagnosis of an inflammatory aneurysm was affirmed intraoperatively and the identification of a small haematoma around the left renal vein supported the likelihood of imminent rupture.
Acknowledgements Regent Lee is a Lumley Travelling Surgical Research Fellow of the Royal Australasian College of Surgeons.

\section{Competing interests None.}

Patient consent Obtained.

\section{REFERENCES}

1. Ngaage DL, Sulaiman MS, Mavor A, et al. Abdominal aortic aneurysm rupture after coronary artery bypass grafting. Cardiovasc Surg 2003;11:237-8.

2. Im JS, Lim YH, Park JS, et al. Rupture of abdominal aortic aneurysm after spine surgery in the patient with Ehlers-Danlos syndrome -A case report-. Korean J Anesthesiol 2010;58:555-9.

3. Cruden NL, Harding SA, Flapan AD, et al. Previous coronary stent implantation and cardiac events in patients undergoing noncardiac surgery. Circ Cardiovasc Interv 2010;3:236-42

4. Hellmann DB, Grand DJ, Freischlag JA. Inflammatory abdominal aortic aneurysm. JAMA 2007;297:395-400.

5. Yabe T, Hamada T, Kubo T, et al. Inflammatory abdominal aortic aneurysm successfully treated with steroid therapy. J Am Coll Cardiol 2010;55:2877.

6. Roy J, Labruto F, Beckman MO, et al. Bleeding into the intraluminal thrombus in abdominal aortic aneurysms is associated with rupture. J Vasc Surg 2008;48:1108-13.

\section{Learning points}

- There is anecdotal evidence on increased risk of AAA rupture after other invasive procedures.

- Surgery for inflammatory AAA is often technically challenging.

- Optimal timing of surgery for large AAA with recent coronary intervention for ACS is difficult to determine.

- Such patients should be under very close surveillance so vascular surgical team can respond promptly to any changes in clinical status.

This pdf has been created automatically from the final edited text and images.

Copyright 2011 BMJ Publishing Group. All rights reserved. For permission to reuse any of this content visit http://group.bmj.com/group/rights-licensing/permissions.

BMJ Case Report Fellows may re-use this article for personal use and teaching without any further permission.

Please cite this article as follows (you will need to access the article online to obtain the date of publication).

Lee R, Bratby M, Uberoi R, Handa A, Hands L. Between a rock and a hard place. BMJ Case Reports 2011;10.1136/bcr.03.2011.3995, date of publication

Become a Fellow of BMJ Case Reports today and you can:

- Submit as many cases as you like

- Enjoy fast sympathetic peer review and rapid publication of accepted articles

- Access all the published articles

- Re-use any of the published material for personal use and teaching without further permission

For information on Institutional Fellowships contact consortiasales@bmjgroup.com

Visit casereports.bmj.com for more articles like this and to become a Fellow 